\title{
Analysis of frequency of congenital fetal anomalies diagnosed on antenatal ultrasound in a tertiary care hospital of Balochistan
}

\author{
Ameet Jesrani $^{1}$, Pari Gul ${ }^{2 *}$, Shama Jogezai ${ }^{3}$, Palwasha Gul ${ }^{2}$, Fahmida Naheed ${ }^{3}$, Asif Jamal ${ }^{1}$
}

${ }^{1}$ Department of Radiology, Sindh Institute of Urology and Transplantation, Karachi, Pakistan
${ }^{2}$ Department of Radiology, Bolan Medical Complex Hospital, Quetta, Pakistan
${ }^{3}$ Department of Obstetrics and Gynecology, Bolan Medical Complex Hospital, Quetta, Pakistan

Received: 15 July 2019

Revised: 03 September 2019

Accepted: 11 September 2019

\section{*Correspondence:}

Dr. Pari Gul,

E-mail: pari.gul01@gmail.com

Copyright: () the author(s), publisher and licensee Medip Academy. This is an open-access article distributed under the terms of the Creative Commons Attribution Non-Commercial License, which permits unrestricted non-commercial use, distribution, and reproduction in any medium, provided the original work is properly cited.

\section{ABSTRACT}

Background: The objective of our study is to check the incidence of various congenital fetal anomalies in antenatal period by ultrasonography in a subset of population.

Methods: This cross sectional study was conducted in the department of Radiology, Bolan Medical Complex Hospital Quetta from November 2017 to October 2018. Total of 1323 second and third trimester pregnancies were analyzed for a period of one year. 34 fetal anomalies were detected making the prevalence of $2.5 \%$. Information obtained from history, clinical examination and Ultrasound examination were recorded. The data was analyzed in SPSS 20.These patients were also interviewed for folic acid supplementation and consanguineous marriage.

Results: 1323 patients were examined with congenital abnormalities detected in 34 fetuses. Among 34 fetuses, 20 were male and 14 were female fetuses. Out of 34, mother of 24 fetuses verified that they did not take folic acid supplementation. Consanguineous marriage recognized as the important risk factor as found in 22 congenital abnormal fetus. CNS anomalies were the most commonly occurring anomalies with prevalence of $(0.9 \%)$ followed by gastrointestinal tract anomalies $(0.3 \%)$ and Urinary tract anomalies $(0.3 \%)$.

Conclusions: The fetus prognosis largely depends on early detection of its any congenital anomaly on antenatal ultrasound as they can result in abortions, still births and other fetal defects. So antenatal ultrasound is very important and safe method for early detection and management of fetal anomalies.

Keywords: Abortions, Antenatal ultrasound, Congenital, Fetal anomalies, Folic acid, Risk factor

\section{INTRODUCTION}

The development of human body entails growth from single cellular structure to multicellular, multi-systematic human body. Fertilization process starts by union of ovum and sperm which results in formation of zygote. After that germinal stage of development commences it comprises with an intricate complex process. Fortunately, most of these go through this process without any hindrance or any unpredictable event. However, some of these fetuses undergo into a misfortunate event resulting in malformed fetus which becomes unfortunate for family and society. Some factors affect the mother like pathogens, increase stress level, lack of proper nutrition, extensive use of certain chemicals and some teratogenic medicines by the mothers can lead to birth of malformed baby. 
According to WHO, Congenital anomalies can result from alteration in functional or structural status of fetus during intrauterine life and it can be diagnosed during prenatal period, at time of birth, or sometimes may in infancy period. So congenital refers to presence of anomaly before or during birth. ${ }^{2}$

Congenital anomalies are major disorders currently affecting countries around the globe. Every year an estimated 7.9 million children are born with a serious birth defect, 3.3 million children (under five years) die from birth defects, and 3.2 million who survive may develop a disability later in the life. ${ }^{3}$ This large number indicates the necessity of preventive measures. These anomalies are preventable in $60 \%$ of cases. ${ }^{4,5}$ The causes of congenital malformation include genetic, environmental or unknown. In genetic causes, abnormalities in chromosomes accounts for $6 \%$, disorders in single gene accounts for $25 \%$ and $20-30 \%$ are multifactorial. Unknown etiology is responsible for $50 \%$ of cases. ${ }^{5}$ Congenital anomalies are classified into major and minor anomalies. Major anomalies involves the vital organs however minor anomalies involve non vital organs with little or no functional effects. Minor anomalies do not result in any distress in the newborn or life threatening condition. Generally they do not require the urgency for their correction especially in the neonatal period. In contrast, major or severe anomalies can be life threatening. These anomalies may result in impairment of major function or may require significant cosmetic interventions. Most of these anomalies require immediate correction. Some major anomalies should be corrected immediately otherwise may result in child casualty or impairment of child well increase stress level being and development. A prenatal diagnosis is possible in $2^{\text {nd }}$ trimester on maternal sonography. ${ }^{6,7}$

\section{METHODS}

The study was conducted in the department of radiology, Bolan Medical Complex Hospital Quetta. 1323 Ultrasound examinations were recorded during the 1 year period between November 2017 to October 2018. Second and third trimesters pregnancies were selected with age of 18-35 years referred from department of Obstetrics and Gynecology. $2^{\text {nd }}$ and $3^{\text {rd }}$ trimesters pregnant patients were included who visit for routine checkup and history of suspected anomalies on clinical exam. Exclusion criteria depend upon discrepancy between uterus size and duration of amenorrhea. Women from all socioeconomic background were included. A detailed history of any risk factors, folic acid intake, family history of congenital anomalies and history of consanguinity were taken. Two Radiologists of more than five years of experience supervised all these ultrasounds. Commercially available ultrasound systems (TOSHIBA, ALOKA) with curved transducers having frequency of $3.5 \mathrm{MHz}$ were used. Based on the ultrasound findings, antenatal diagnoses of congenital disorders were made. The reports and findings were recorded. The prescribed proforma was filled.

\section{Statistical analysis}

The data was analyzed by SPSS-20. These patients were referred to other specialties for further management.

\section{RESULTS}

1323 patients were scanned in a tertiary care hospital over a period of about 1 year. Out of 1323 fetal ultrasounds, 34 had various congenital anomalies making a incidence of $2.5 \%$.

Table 1: Distribution of structural abnormalities detected on antenatal ultrasound.

\begin{tabular}{|lll|}
\hline Musculoskeletal & Number & Percentage \\
\hline GIT & 3 & 0.2 \\
\hline Cardiac & 5 & 0.3 \\
\hline Urinary & 1 & 0.1 \\
\hline CNS & 4 & 0.3 \\
\hline Facial defects & 12 & 0.9 \\
\hline Multiple anomalies & 3 & 0.2 \\
\hline $\begin{array}{l}\text { Miscellaneous (cystic } \\
\text { Hygromas) }\end{array}$ & 3 & 0.2 \\
\hline
\end{tabular}

Out of 34 fetuses, there were 20 male and 14 female, showing more prevalence in male population.

The consanguinity rate in mothers having abnormal fetal ultrasound was seen in 22 congenital abnormal fetus $(64.5 \%)$. Out of 34 mothers only 8 were using folic acid. However those mothers who have had normal fetal ultrasounds were using folic acid supplementation.

Table 2: Distribution of maternal age in years.

\begin{tabular}{|lll|}
\hline Maternal age in years & Number & Percentage \\
\hline $20-24$ & 6 & $20 \%$ \\
\hline $25-29$ & 17 & $50 \%$ \\
\hline $30-34$ & 10 & $29 \%$ \\
\hline$<35$ & 1 & $2 \%$ \\
\hline
\end{tabular}

Table 1 shows the distribution of structural abnormalities detected on antenatal ultrasound. CNS anomalies were the most commonly occurring anomalies with prevalence of $(0.9 \%)$ followed by gastrointestinal tract anomalies $(0.3 \%)$ and Urinary tract anomalies $(0.3 \%)$. In 3 of the cases fetus showed multiple anomalies both renal and CNS malformation. Facial defects including cleft lip and palate, multiple anomalies and cystic hygromas constituted $0.2 \%$ of cases. Only one case of cardiac anomaly (Teratology of Fallot) was seen making it the least prevalent anomaly in antenatal period. Other reason can be the lack of expertise to diagnose cardiac anomalies.

The mean age of the mothers whose fetus were diagnosed as anomalous fell in the range of $25-29$ years $(50 \%)$. The 
late presentation was of a 37 years old patient with anencephalic fetus (Table 2).

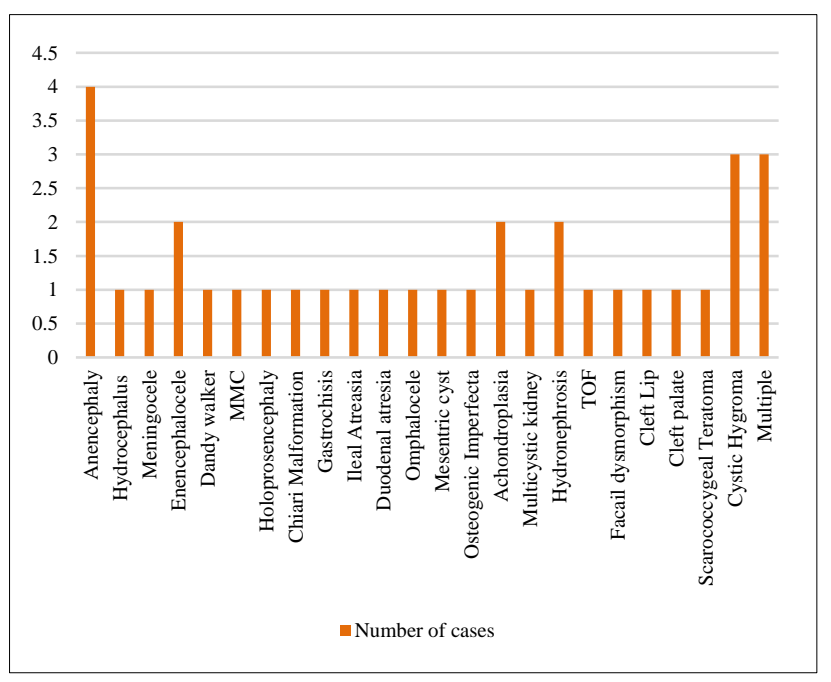

Figure 1: Congenital disorders and their frequencies.

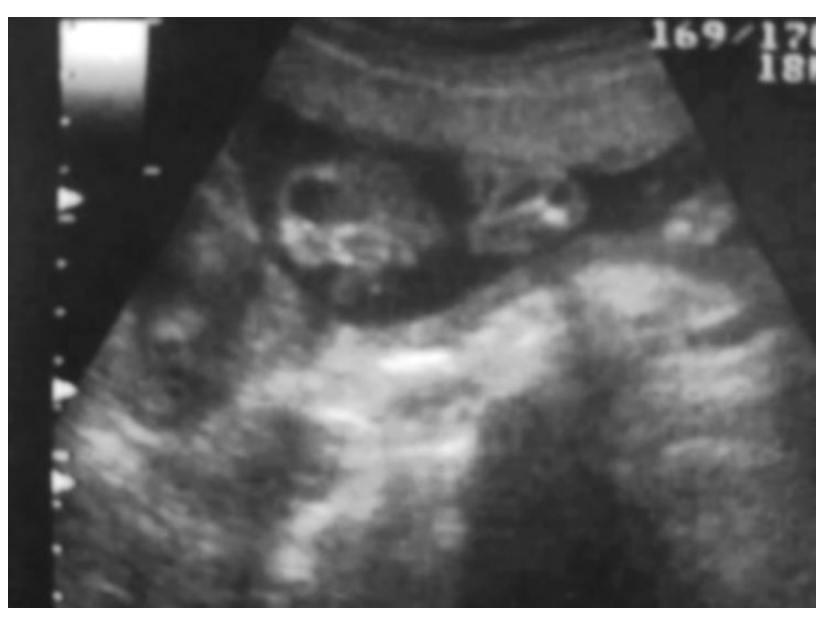

Figure 2: Anencephaly in 27 weeks fetus with absent cranium and prominent orbits.

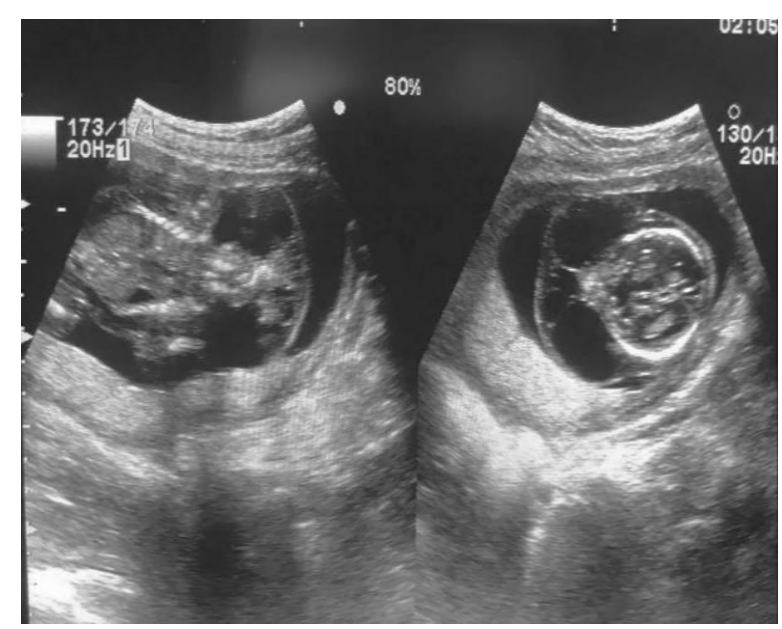

Figure 3: Cystic hygroma (Nuchal cyst with septations) in 18 weeks old fetus.

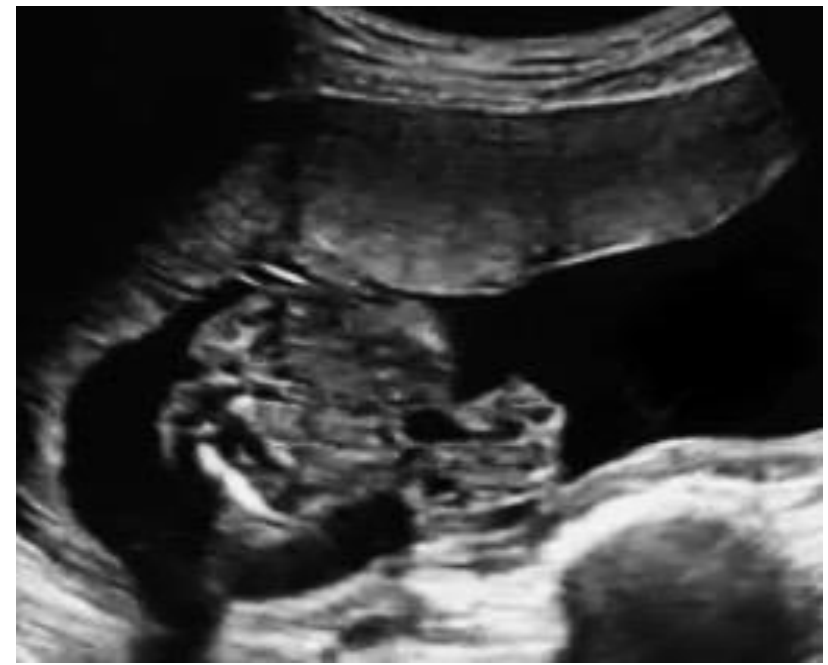

Figure 4: A 20 weeks fetus showing bowel loops outside the abdominal cavity (Gastroschisis).

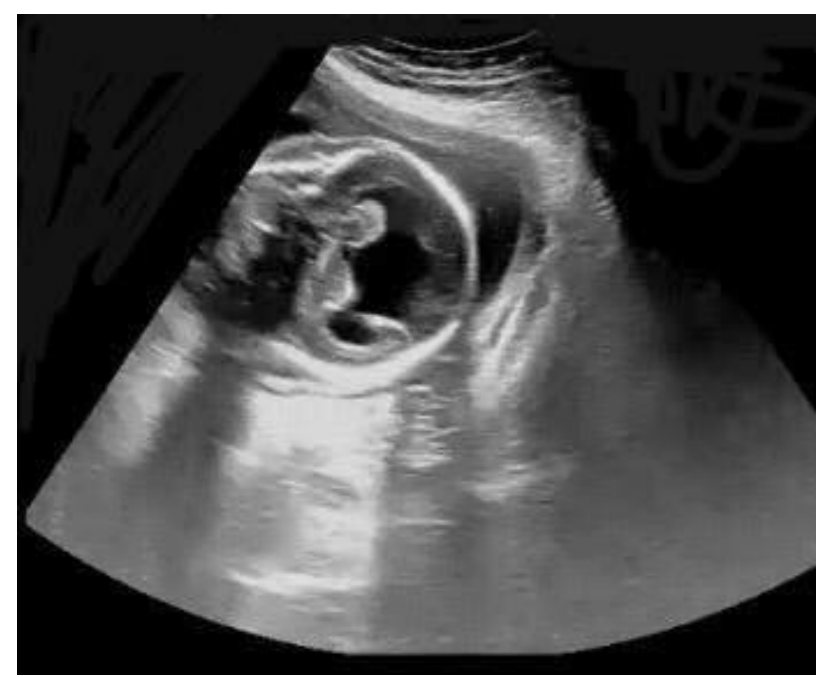

Figure 5: Monoventricle with fused Thalami in a 21 weeks fetus (Holoprosencephaly).

Figure 1 describes the anomalies with their frequency. Anencephaly was the most common CNS anomaly constituting 4 cases out of 12 cases (Figure 2). Three cases of cystic hygroma were identified making it one of the common anomaly in antenatal period (Figure 3). There were five cases of GIT anomalies of which gastroschisis was seen in a 20 weeks fetus (Figure 4). Holoprosencephaly was also one of the rare CNS anomaly seen (Figure 5).

\section{DISCUSSION}

Congenital anomalies, also commonly referred to as birth defects, congenital disorders or congenital malformations. These anomalies usually develop before birth and are present at the time of birth and they can affect infant's health which can be life threatening. ${ }^{8}$ Congenital malformation varies from region to region. Prevalence of congenital malformation in our study is 
$2.5 \%$. However, worldwide prevalence is $3-7 \%$. Its prevalence depends on geographic distribution, socioeconomic condition, ethnicity, region of study and last but not the least is nature of sample. ${ }^{9}$ Studies in different part of world showing difference prevalence results. One study showed prevalence of congenital anomalies in Oman found $2.46 \%$ while it is $4.3 \%$ in Taiwan. ${ }^{10}$ In India; its prevalence is $1.7 \% .{ }^{11}$ Prevalence of congenital malformation according to the systems is different in different region. For example, one study is Iran showed that musculoskeletal anomalies (27.5\%) are the most occurring anomalies followed by skin anomalies $(19.7 \%)$ and genitourinary system anomalies (15.8\%). However, the respiratory system anomalies have the lowest prevalence $(1.82 \%){ }^{12}$ Another study that was done in Europe, there were 17 anomaly subgroups with significant trends at the $5 \%$ level of significance; Increasing trend was noted for 12 anomalies (severe CHD, single ventricle, atrioventricular septal defects, tetralogy of Fallot, cystic adenomatous malformation of lung, esophageal atresia, duodenal atresia/stenosis, anorectal atresia/stenosis, renal dysplasia, club foot, craniosynostosis and maternal infections resulting in malformations). However, five subgroup were on decreasing trend.(microcephaly, patent ductus arteriosus, congenital hydronephrosis, limb reduction and syndactyly). This study showed the trend of last 10 years and concluded the fact that the prevalence of neural tube defects as a group, and spina bifida and anencephaly individually, did not show a significant change but the slight reduction. ${ }^{13}$ Another study that was done in Saudi Arabia showed that the CNS anomalies are the most occurring anomaly followed by musculoskeletal and then renal system anomalies. ${ }^{14}$ One study that was done in Brazil showed that the congenital anomalies are more prevalent in male as compared to female (59\% male newborn and $41 \%$ in female newborn). ${ }^{15}$

Fetal wellbeing monitoring is necessary to assess the status of fetus. So routine use of prenatal ultrasound (PNUS) has been standardized. The rationale for PNUS is to make an approach securing the health of embryo or fetus. It also detects congenital anomalies, placental abnormalities, fetal growth disorder and multiple pregnancies. Prenatal ultrasound is also done to establish the gestational age and viability of fetus. ${ }^{16-18}$ Ultrasound machines have been developed more efficiently with their software advancements. All these changes made ultrasound machine very reliable and safer modality that can manipulate the images for accurate interpretations. However, training of personnel is necessary to gather and interpret images. Participation of specialists like perinatology and maternal medicine is also worth mentioning. All these factors may result in diagnosing virtually the $100 \%$ congenital anomalies before birth. ${ }^{18}$ Prenatal diagnosis affects the society and patient in many ways. It improves the affected newborns outcome. First it prepares the family to accept the newborn with malformation. It also helps the family to prepare for long term care or need for urgent surgical correction. Second, it may allow for in utero intervention. Last, antenatal diagnosis of malformation may also prepare the hospital, particularly the neonatology team in advance to care the newborn. ${ }^{16,18,19}$ Many methods of primary prevention have been implemented and following these methods may result in reduction of prevalence of congenital anomalies. Risk factors for congenital malformation have also been scientifically known like obesity, infections and toxic agents. Some protective measures are also scientifically proven like glycemic control in diabetic women. ${ }^{20}$ Folic acid supplementation before conception and during pregnancy plays very important role in preventing congenital defects (Neural Tube Defects). ${ }^{21}$

Fate of congenital anomalies is variable. Some defects may completely cured by surgery while others may requires subsequent surgeries of long term disabilities which is quite stressful for family also a burden for hospital resources. Some can be life threatening and some can achieve the improvement in functions and quality of life. World Health Organization and other international bodies address congenital malformation as prioritizing public health issue. Especially in developing countries, early recognition of congenital malformation is necessary with proper preventive measures and management. These measures can improve the overall status of the newborn. ${ }^{22}$ Congenital malformation may result in fetal death or still birth. If congenital malformation is diagnosed early, it will definitely help the further management of fetus or new born. Proper planning, installation of specialized equipment, timely referral and care of mother and fetus will definitely make difference in the outcome of new born with congenital anomaly. It will help further management and planning of fetal outcome. Timely referral and installation of specialized equipment in government based hospital will definitely make difference in the outcome of newborn and ultimately will result in healthy society.

\section{CONCLUSION}

Antenatal ultrasound is the cost effective modality to diagnose the congenital malformation. It is the safe, accurate and non-invasive method. It has become the modality of choice to monitor fetal wellbeing. In addition to awareness of folic acid supplementation before and after conception, the meticulous and regular antenatal ultrasound screening is mandatory for pregnant females which can help to diagnose the congenital malformation.

In this way, authors can reduce the state expenditure and unexpected mental trauma to family having a handicapped child. This can play a pivotal role in the healthy and normal birth.

\section{Funding: No funding sources}

Conflict of interest: None declared

Ethical approval: The study was approved by the Institutional Ethics Committee 


\section{REFERENCES}

1. Dolk H. Epidemiological approaches to identifying environmental causes of birth defects. Am J Med Genet C Semin Med Genet. 2004;125C(1):4-11.

2. Congenital Anomalies. Available at: https://www.who.int/news-room/fact-sheets/detail/ congenital-anomalies.

3. Carmona RH. The global challenges of birth defects and disabilities. The Lancet. 2005;366(9492):1142-4.

4. Czeizel AE. Prevention of congenital abnormalities by periconceptional multivitamin supplementation. Br Med J. 19993;306(6893):1645-8.

5. Balakumar K. Antenatal ultrasound screening for anomalies among singletons result of a prospective study. Calicut Med J. 2004:2;1-10.

6. Singh S, Shergill A, Singh R. Role of ultrasound in detection of antenatal fetal malformations. Ind $\mathrm{J}$ Radiol Imag. 2006;16:831-34.

7. Boyle CA, Cordero JF. Birth defects and disabilities: a public health issue for the 21 st century. Am J Public Health. 2005:95:1884-6.

8. Park K. Congenital malformations. In: K Park(Ed). Park's Text book of Preventive and Social Medicine.15th edition. Banarsidas Bhanot Publishers; 2005:379-80.

9. Tayebi N, Yazdani K, Naghshin N. Prevalence of congenital malformations and its correlation with consanguineous marriages. Oman Med J. 2010;25:37-40.

10. Singh A, Gupta RK. Pattern of congenital anomalies in newborn: A hospital based prospective study. JK Sci. 2009;11:34-6.

11. Vatankhah S, Jalilvand M, Sarkhosh S, Azarmi M, Mohseni M. Prevalence of congenital anomalies in Iran: A Review Article. Iran J Public Health. 2017;46(6):733-43.

12. Morris JK, Springett AL, Greenlees R, Loane M, Addor MC, Arriola L, et al. Trends in congenital anomalies in Europe from 1980 to 2012. PLoS ONE. 2018;13(4):e0194986.

13. Asindi AA, Al Hifzi I, Bassuni WA. Major congenital malformations among Saudi infants admitted to Asir central hospital. Ann Saudi Med 1997; 17:250-3.
14. Oliveira CI, Costa AR, Ferrarese VCC, Mozvaz DC, Fett-conte AC. Birth defects in newborns and stillborns: An example of the Brazilian reality. BMC Notes. 2011;4:343.

15. Ewigman B, Crane J, Frigoletto F, LeFevre M, Bain $\mathrm{R}$, McNellis D. Effect of prenatal ultrasound screening on perinatal outcome. $\mathrm{N}$ Engl $\mathrm{J}$ Med. 1993;329:821-7.

16. Whitworth M, Bricker L, Neilson JP, Dowswell T. Ultrasound for fetal assessment in early pregnancy. Cochrane Database Syst Rev. 2010;(4):CD007058.

17. Saldarriaga W, Artuz A. Ayudas Diagnósticas en Obstetricia. En. Colombia: Universidad del Valle Programa Editorial; 2010.

18. Campaña H, Ermini M, Aiello H, Krupitzki H, Castilla E, López-Camelo J. Prenatal sonographic detection of birth defects in 18 hospitals from South America. J Ultrasound Med. 2010;29:203-12.

19. DMantovani A, Carbone P, Barisic I, Bianchi F, Garne E, Nelen V, et al. Primary prevention of congenital anomalies: recommendable, feasible and achievable. Public Health Genomics. 2015;18:184-91.

20. Bortolus R, Blom F, Filippini F. Prevention of congenital malformations and other adverse pregnancy outcomes with $4.0 \mathrm{mg}$ of folic acid: community-based randomized clinical trial in Italy and the Netherlands. BMC Preg Childbirth. 2014;14:166.

21. Wald NJ. Folic acid and the prevention of neural-tube defects. N Engl J Med. 2004 Jan 8;350(2):101-3.

22. DeSilva M, Munoz FM, Mcmillan M. Congenital anomalies: Case definition and guidelines for data collection, analysis, and presentation of immunization safety data. Vaccine. 2016;34(49):6015-26.

Cite this article as: Jesrani A, Gul P, Jogezai S, Gul $P$, Naheed F, Jamal A. Analysis of frequency of congenital fetal anomalies diagnosed on antenatal ultrasound in a tertiary care hospital of Balochistan. Int J Reprod Contracept Obstet Gynecol 2019;8:3976-80. 